The possibility of a specific, dirty-hands dilemma does not justify a policy that regularly violates LEE.

In a provocative final chapter (ch. 12), Deen Chatterjee questions the entire premise of using preventive force to combat terrorism. If we are serious about prevention, says Chatterjee, we should seek nonmilitary ways of preventing terrorism from arising in the first place. To this end, he calls for a shift in priorities to proactive policies, which he terms a "just-peace approach." We must address the deeper issues of peace and justice, rather than merely consider whether fighting terrorism requires a loosening of just war principles-the project in which other of the authors are engaged.

The chief reasons for the tensions and resentments that breed terrorism, according to Chatterjee, are poverty, deprivation, and humiliation; hence, we must attack these problems with economic development and political accommodation. To be sure, this justpeace approach cannot guarantee total security, but neither does the policy of preventive military intervention that has been counterproductive, causing much resentment and distrust toward the United States.

None of this is to diminish the work of the other authors in the collection, but Chatterjee's contribution is an urgent call to take a step back from the counterterrorism framework that informs the rest of the volume, and as such it is a fitting final contribution. Chatterjee's vision is that of a global culture that undertakes collaborative efforts to promote just peace by directly addressing the socioeconomic conditions of poverty and inequality. He recognizes that this will take much time and political will. Nevertheless, the sooner we make this our first priority, the better hope we may have for the future.

\section{-Don SCHEID}

Don E. Scheid is Professor of Philosophy, Emeritus, at Winona State University. His main areas of research and publishing are philosophy of criminal law, terrorism law, and the philosophy of international law concerning the use of armed force.

Rethinking the New World Order, Georg Sørensen (London: Palgrave, 2016), 264 pp., $\$ 120$ cloth, \$48 paper.

doi:10.1017/So892679417000119

The defining question of world order today is whether the rapid shifts in the global balance of power make war between rising and dominant powers very likely. The master narrative of the past seventy-two years, for many, has revolved around the idea of a U.S.-led post-World World II liberal hegemonic order with three key characteristics:
(1) maintain global order; (2) provide public goods in the key areas of security, economy, and finance; and (3) maintain a gravitational normative pull, generating a large enough following to sustain U.S. leadership.

With relative power now shifting horizontally from the West to the rest, and 
diffusing vertically to nonstate actorsranging from corporations to WikiLeaks to terrorists-the U.S.-led liberal order is challenged, as it is no longer seen as the master framework through which to organize global international relations. According to Graham Allison, over the past five hundred years twelve out of sixteen cases of power transition resulted in war, making it more the rule rather than the exception. While the idea of global community (with shared destiny) is perhaps now invoked more often than at any point in the past, there is no mutually agreed set of rules and principles for how societies should be organized and relate to one another.

The challenges of order transition are compounded by the interconnected complexity of today's global issues, heightened by rapid technological advancement, all of which makes government and governance harder. At the same time, the policy space of state actors is shrinking.

Georg Sørensen's Rethinking the New World Order picks up many of those central themes and provides an elegant account of the nature and inherent tensions of global order a quarter century after the cold war. It starts from the claim that the major fault line in the contemporary world order debate is "the division between liberal optimists and sceptical realists" (p. 2). While some, especially those working in the constructivist tradition of international relations (IR), may disagree, Sørensen convincingly argues that each school of thought tends to offer-borrowing from Isaiah Berlin-a "hedgehog" analysis focusing on just "one important thing" as the central feature that makes the world hang together.

In order to overcome such conceptual and analytical biases, Sørensen holds that any study on order needs to utilize a "fox" analysis, embracing the multiple major dimensions of global order in transition. The point is well made, but he pushes the limits of Berlin's classification, which was meant to be a light-hearted intellectual stimulus, a tad too far by effectively introducing two subspecies of foxes. One is what I will call the "radical" fox, who analyzes world order through "an endlessly complex collection of structures, actors, and processes" (p. 28). According to Sørensen, this is prominently exemplified in the academic writings of Andrew Hurrell and Barry Buzan, whose works are rich but ultimately fail to deliver a clear picture on the nuts and bolts of world order. The other is what I will call the "moderate" fox-with whom Sørensen himself identifies-who seeks to offer a middle ground between the hedgehog and the radical fox. Thus, the author engages with ongoing theoretical debate among liberal optimists and skeptical realists, while at the same time examining broader structures, actors, and processes that are considered central to the understanding of world order.

There is much to commend about Rethinking the New World Order. First, the author is committed to bridging the methodological and ontological divides in the field of international relations. Additionally, he makes a bold attempt to break the domestic-international conceptual divide in IR by highlighting that analysis of world order is both a global and domestic affair. Finally, he is dedicated to theoretical pluralism, avoiding much of the excessive parsimony of the main IR schools of thought.

However, in some places Sørensen remains stuck in the hedgehog-fox divide that he is so intent on avoiding, and this confines and constrains his otherwise erudite analysis. Three issue areas in particular illustrate this shortcoming: the fragility of states, the decreasing importance of 
interstate war, and economic globalization (chapters 2, 3, and 6, respectively).

First, Sørensen carefully demonstrates that the advanced capitalist states in the Global North, the modernizing rising BRICS economies, and "the weak states" of the Global South are all fragile "in the sense that they have problems with sociopolitical cohesion" (p. 54). Hence, addressing the domestic conditions in those three major types of states is a sine qua non for the stability and the maintenance of world order. However, there is much more to say. Governments also have to deal with the adverse effects of a shrinking policy space while at the same time being forced to account for the interconnectedness of policy issues. Collective action problems must be analyzed and addressed in their wider systemic context. Rather than navigating dyadic and polyadic diplomatic relationships in achieving policy outcomes, governments must find ways to navigate the whole system.

Second, the assumption of "a consensus on the futility of interstate war, especially among great powers" (p. 78) is a view far too cozy. At the regional level, nowhere is the struggle for order and peaceful cooperation more pronounced than in East Asia. Despite having enjoyed a period of relative peace since 1979, the presence of many deep-seated and unresolved postcolonial and cold war-era divisions, as well as tensions over territorial and resource struggles, mean the region may well become a theater of armed conflict among major powers. Any consensus on the futility of interstate war should not be taken for granted. Conflict between the United States and China is possible. Europe's self-destruction in the first half of the twentieth century should temper undue faith in the ability of two countries to make rational decisions to avoid war. It will take a much more strategic approach to diplomacy by the key actors and institutions to defeat the logic of great power conflict and escape the Thucydides Trap.

Third, regarding economic globalization, Sørensen posits that the liberal model is essentially underwritten by "the comfortable middle class" (p. 213) in North America, Western Europe, and Japan, a group that has come under increasing pressure after the global financial crisis of 2008 . Yet, one could argue-perhaps more convincingly - that the future of Western capitalism, which is part and parcel of the New World Order, ultimately will be decided in the East rather than the West. With the middle class in Asia expected to triple to 1.75 billion by 2020 , the region is currently witnessing what the United Nations describes as a historic shift not seen in the last 150 years. Since non-Asian economies will increasingly have to rely on the middle-class populations of the Asia-Pacific, this shift constitutes one of the most important features of today's economic landscape. It is their choices and preferences that will drive the dynamics of economic globalization.

Nevertheless, Rethinking the New World Order should be read by all hedgehogs and foxes with an interest in today's world disorder because, ultimately, it is only the enlightened collaboration between them that can save us from a far fiercer creature, the black swan.

\section{-Jochen Prantl}

Jochen Prantl is deputy director of the Coral Bell School of Asia Pacific Affairs and associate professor in international relations at the Australian National University. 